\title{
Perfil do gestor e práticas de gestão municipal no Sistema Único de Saúde (SUS) de acordo com porte populacional nos municípios do estado do Rio Grande do Sul
}

\author{
Manager profile and practices of county health management \\ in the Unified Health System (SUS) according to population size \\ in the municipalities of the Rio Grande do Sul state
}

Janete Madalena Arcari (https://orcid.org/0000-0003-2688-0686) ${ }^{1}$

André Phylippe Dantas Barros (https://orcid.org/0000-0002-1413-0418) ${ }^{2}$

Roger dos Santos Rosa (https://orcid.org/0000-0002-7315-1200) ${ }^{1}$

Renato De Marchi (https://orcid.org/0000-0002-7600-1240) ${ }^{3}$

Aline Blaya Martins (https://orcid.org/0000-0001-6300-068X) ${ }^{4}$
${ }^{1}$ Programa de Pós-

Graduação em Saúde

Coletiva, Universidade

Federal do Rio Grande do

Sul. R. São Manoel 963, Rio

Branco. 90620-110 Porto

Alegre RS Brasil.

janete_arcari@yahoo.com.br

${ }^{2}$ Faculdade de Farmácia,

Universidade Federal do Rio

Grande do Sul. Porto Alegre

RS Brasil.

${ }^{3}$ Faculdade de Odontologia, Universidade Federal do Rio

Grande do Sul. Porto Alegre

RS Brasil.

${ }^{4}$ Departamento de

Odontologia Preventiva e

Social, Universidade Federal

do Rio Grande do Sul. Porto

Alegre RS Brasil.

\begin{abstract}
This study intended to gather who are the county health managers and the practices performed in management. It is based on a cross-sectional design. The methodology involved the use of electronic questionnaire, which was sent to the health departments of the 497 municipalities of the state of Rio Grande do Sul (RS). Of these, 297 were answered (59.75\%). However, only those with more than $50 \%$ of valid answers ( $n$ $=264)$ were included in the statistical analysis. The analysis included the calculation of the distribution of variables and chi-square testes, taking population size as an independent variable. Most managers were women; graduated; from different professional backgrounds; average age of 43.76 years-old, and white. The average health expenditure in the municipalities was $\approx 20 \%$ of revenues. There was a consensus on the insufficiency of resources. With regards to population size, 79.92\% presented with $\leq 20,000$ inhabitants. Statistically significant differences were found in the management of municipalities of different sizes, both in terms of priorities and difficulties. The study allowed to partially understanding the reality of municipal management. These results indicate the need to further investigate the feminization of health management, working process assessment, and the impacts of economical austerity policy.

Key words Health Management, County Health Departments, Decentralization, Unified Health System
\end{abstract}

Resumo O estudo buscou conhecer quem são os gestores municipais de saúde e práticas realizadas no âmbito de gestão. Possuiu delineamento transversal. A metodologia contou com o envio de um questionário eletrônico às secretarias de saúde dos 497 municípios do estado do Rio Grande do Sul (RS). Destes, 297 retornaram (59,75\%). Contudo, foram considerados na análise estatística apenas os questionários com mais de $50 \%$ de respostas válidas $(n=264)$. A análise contou com o cálculo da distribuição das variáveis e com testes de qui-quadrado, onde o porte populacional foi considerado variável independente. A maioria foi composta por mulheres, com escolaridade alta e distintas formações, média de idade de 43,76 anos, cor branca. A média de gastos com saúde foi de $\approx 20 \%$ das receitas. Houve consenso quanto na insuficiência dos recursos. Quanto ao porte populacional, 79,92\% possuíam $\leq 20.000$ habitantes. Diferenças significativas foram observadas na gestão de municípios de distintos portes, tanto nas prioridades, quanto nas dificuldades. O estudo permitiu conhecer parcialmente a realidade da gestão municipal. Além disso, os resultados sugeriram a necessidade de novas pesquisas sobre a feminilização da gestão, avaliação de processos de trabalho e impactos da politica de austeridade.

Palavras-chave Gestão em Saúde, Secretários Municipais de Saúde, Descentralização, Sistema Único de Saúde 


\section{Introdução}

A descentralização do Sistema de Saúde, proposta pela Constituição Federal de 1988, tornou a gestão do sistema uma responsabilidade compartilhada pela União, Estados e Municípios, respeitando a autonomia de cada ente federado e com decisões baseadas em consenso. Sendo um dos princípios organizativos do Sistema Único de Saúde (SUS), a descentralização remete a avanços significativos na construção do SUS pois rompe com o modelo centralizado na assistência e redistribui recursos e responsabilidades entre os entes federados, objetivando uma prestação de serviços com mais eficiência e qualidade e também a fiscalização e o controle por parte da sociedade.

Durante a década de 1990 ocorreram os principais avanços do processo de descentralização do setor saúde no Brasil e junto surgiram inúmeros desafios. A esfera municipal tornou-se a principal responsável pela gestão da rede de serviços de saúde no país e os gestores municipais assumiram papel fundamental para execução das ações e serviços de saúde atendendo as particularidades de cada região ${ }^{2}$.

O Brasil possui uma grande diversidade de características na conformação de seus municípios, sendo este um dos fatores que contribuíram para que a descentralização não ocorresse de forma homogênea. Este mesmo fator interferiu também na capacidade dos municípios em assumir a gestão. Mesmo assim, a descentralização favoreceu novos arranjos institucionais com a promoção de ações intersetoriais integradas, diminuindo a fragmentação das ações e fortalecendo a parceria com outros níveis de governo e com governos de outros municípios ${ }^{3,4}$. Os municípios do Estado do Rio Grande do Sul seguem a tendência e também possuem grande diversidade em suas características. Apresentam um expressivo número de municípios de pequeno e médio porte ${ }^{5}$.

Reflexões trazendo à luz a complexidade da gestão pública do SUS, nos municípios que possuem diferentes portes populacionais, englobam temas diversos como a organização da assistência à saúde da população, questões burocráticas, judiciais, distintos perfis profissionais na assistência e na gestão e até mesmo a capacidade de formação de recursos humanos. Desta forma, o objetivo desta pesquisa foi conhecer quem são e como atuam os gestores municipais de saúde no estado do Rio Grande do Sul, quando distintos portes populacionais são considerados.

\section{Metodologia}

\section{Delineamento}

Estudo observacional, quantitativo, de caráter descritivo e com delineamento transversal.

\section{Cenário do Estudo}

O Estado do Rio Grande do Sul que é composto por 497 municípios, ocupa uma área de $281.737,947 \mathrm{~km}^{2}$, com população estimada para 2016 de 11.286.500 habitantes, tendo a maioria das cidades de pequeno porte mais de $78 \%$ de população inferior a 20 mil habitantes. Registra-se 329 municípios (66,2\%) com até 10.000 habitantes. Esses dados estabelecem os pequenos municípios como um dos principais protagonistas pela gestão do SUS no Estado do Rio Grande do Sul'.

O Rio grande do Sul está dividido em 30 Regiões de Saúde ${ }^{7}$, distribuídas nas 19 Coordenadorias Regionais de Saúde (CRS) que desempenham a função de coordenação político-administrativa. Elas são responsáveis pelo planejamento, acompanhamento e pelo gerenciamento de ações e de serviços de saúde mediante a cooperação técnica e operacional realizada com os gestores municipais e prestadores de serviços.

\section{Medida}

O instrumento de coleta das informações foi um questionário estruturado contendo 43 questões, não identificado e autoaplicável tomando como unidade de análise os Secretários Municipais de Saúde do estado do Rio Grande do Sul.

A versão final do questionário foi elaborada pela equipe de pesquisadores responsável por este estudo, a partir de trabalhos anteriores ${ }^{8,9}$ definindo três focos de análise: "o gestor, abordando questões referentes ao perfil pessoal, educacional e profissional dos secretários municipais de saúde"; "as características do município onde atua"; "processo de gestão".

O perfil do gestor foi estabelecido através das seguintes variáveis: sexo, idade, raça/cor, grau de escolaridade, profissão, tempo no cargo na atual gestão, vínculo empregatício, reside no município onde é gestor ( $\operatorname{sim} /$ não), experiência pregressa como secretário municipal de saúde ( $\operatorname{sim} /$ não) e filiação partidária ( $\operatorname{sim} /$ não).

O município foi caracterizado quanto ao seu porte populacional aferido pela pergunta "Qual a população estimada do seu município?”, com 
as seguintes respostas possíveis: “ $\leq 5.000$ habitantes (hab.)", “5.001 até 10.000 hab.", “10.001 até 20.000 hab.”, “20.001 até 50.000 hab.”, “50.001 até 100.000 hab., " 100.001 até 500.000 hab.” e “> 500.000 habitantes". Outra variável atribuída ao município foi a habilitação de saúde através da pergunta, "Qual é a habilitação no seu município?", com as seguintes repostas possíveis: "Gestão Plena de Saúde", "Gestão Plena de Atenção Básica de Saúde" e "Não sei”.

A gestão foi investigada através das seguintes variáveis: Modelo de atenção básica, prioridades da gestão, atuação do Conselho Municipal de Saúde, participação social, adesão aos programas Mais Médicos e Programa de Melhoria do Acesso e Qualidade da Atenção Básica (PMAQ-AB), apoio do Conselho das Secretarias Municipais de Saúde do Rio Grande do Sul COSEMS/RS, gasto com saúde, Emenda Constitucional 29, Lei de Responsabilidade Fiscal e dificuldades ao administrar a secretaria (Quadro 1).

Para fins de análise o porte populacional foi considerado variável independente, tendo sido categorizada, mediante a distribuição, de duas formas: i) categórica (até 10.000 habitantes, entre 10.001 a 20.000 , mais de 20.001 até 500.000), e ii) dicotomizada (até 10.000 habitantes e 10.001 a 500.000).

As demais variáveis foram consideradas dependentes do porte populacional dos municípios.

\section{Coleta de dados}

O instrumento foi enviado para todos os secretários municipais de saúde e respondido por meio eletrônico.

Com o propósito de divulgar a pesquisa e com objetivo de sensibilizar os gestores para a participação, a pesquisadora participou de eventos direcionados aos Secretários de Saúde realizados pelo COSEMS/RS. Em julho de 2016 participou do Congresso das Secretarias Municipais de Saúde do Rio Grande do Sul e em fevereiro de 2017, participou do evento de Acolhimento aos Novos Gestores que foi promovido pelo COSEMS/RS e a Secretaria Estadual de Saúde SES/ RS. Posteriormente, em março de 2017 participou da Reunião da Diretoria e do Conselho Deliberativo do COSEMS/RS para a apresentação da pesquisa aos participantes.

Como a base para pesquisas on-line, é, a priori, uma lista de endereços eletrônicos válidos, buscamos parceria com COSEMS/RS. Houve o contato com o Presidente e obtivemos o apoio e a participação direta no envio de e-mail com um link e o convite para os secretários de saúde dos 497 municípios do Rio Grande do Sul responderem ao questionário, no período de novembro de 2016 a abril de 2017, através dos endereços eletrônicos de suas secretarias.

Foi utilizado o Software Survey Monkey Inc. ${ }^{.}$ para a montagem do instrumento e coleta de dados da pesquisa.

\section{Análise dos dados}

Para a análise estatística dos dados utilizouse o software IBM SPSS v. 21 (Chicago: SPSS), calculadas as frequências de distribuição das variáveis em análise e a diferença entre médias foi atribuída através do teste de qui-quadrado onde foram consideradas significativas as diferenças com o valor $\mathrm{p}<0,05$.

\section{Considerações Éticas}

O projeto de pesquisa foi aprovado pelo Comitê de Pesquisa da UFRGS. Os preceitos éticos e legais foram respeitados seguindo o Conselho Nacional de Ética em Pesquisa.

\section{Resultados}

O instrumento de coleta de dados foi enviado às 497 Secretarias Municipais de Saúde do estado, sendo retornado por 297 (59,8\%) secretários. No entanto, 33 questionários foram excluídos por possuir menos de $50 \%$ de respostas válidas. Portanto, obteve-se uma amostra de 264 participantes $(53,1 \%$ do total de sujeitos que compõem tal população). Ao fazer a análise do grupo de respondentes, houve a participação de gestores de todas as 19 CRS e das 30 Regiões de Saúde.

As características dos gestores participantes desta pesquisa foram: maioria composta por mulheres (58,0\%); nível de escolaridade foi bastante variável, com predomínio $(64,0 \%)$ do nível superior completo; média de idade de 43,76 anos $(\mathrm{dp}=9,11)$ variando entre 22 e 70 anos; o grupo apresentou-se heterogêneo quanto a sua área de formação, porém, houve uma expressiva participação de administradores e enfermeiros; maioria $(93,6 \%)$ de cor branca. Quanto ao vínculo empregatício 147 secretários (55,7\%) possuíam cargo em comissão, enquanto 100 (37,9\%) eram funcionários públicos estatutários, além de outras formas de contratações menos frequentes. A residência no próprio município onde exerce 
Quadro 1. Lista de variáveis construídas com o propósito de caracterizar aspectos/processos pertinentes a gestão que foram investigadas nesta pesquisa.

\begin{tabular}{|c|c|c|}
\hline Variáveis & Questões que deram origem as informações obtidas & Respostas possíveis \\
\hline \multirow[t]{3}{*}{$\begin{array}{l}\text { Modelo de Atenção } \\
\text { Básica }\end{array}$} & \multirow[t]{3}{*}{$\begin{array}{l}\text { Qual o modelo de assistência a atenção básica que é } \\
\text { utilizado no seu município? }\end{array}$} & $\begin{array}{l}\text { Estratégia de Saúde da } \\
\text { Família (ESF) }\end{array}$ \\
\hline & & Outro modelo \\
\hline & & ESF e outro modelo \\
\hline \multirow{2}{*}{$\begin{array}{l}\text { Programa Mais } \\
\text { Médicos atuando no } \\
\text { município }\end{array}$} & \multirow{2}{*}{$\begin{array}{l}\text { Existem médicos do Programa Mais Médicos atuando no } \\
\text { seu município? }\end{array}$} & Sim \\
\hline & & Não \\
\hline \multirow{3}{*}{$\begin{array}{l}\text { Programa Nacional } \\
\text { de Melhoria do } \\
\text { Acesso e Qualidade } \\
\text { da Atenção Básica } \\
\text { (PMAQ-AB) }\end{array}$} & \multirow{3}{*}{$\begin{array}{l}\text { Município aderiu a participação no Programa Nacional } \\
\text { de Melhoria do Acesso e Qualidade da Atenção Básica - } \\
\text { PMAQ-AB? }\end{array}$} & Nenhuma equipe \\
\hline & & Algumas equipes \\
\hline & & Todas as equipes \\
\hline \multirow{2}{*}{$\begin{array}{l}\text { Prioridade da } \\
\text { Gestão: demanda } \\
\text { espontânea }\end{array}$} & \multirow{2}{*}{$\begin{array}{l}\text { A demanda espontânea é um critério utilizado em seu } \\
\text { município para o estabelecimento das prioridades na saúde? }\end{array}$} & Sim \\
\hline & & Não \\
\hline \multirow{2}{*}{$\begin{array}{l}\text { Prioridade da } \\
\text { Gestão: opinião do } \\
\text { corpo técnico }\end{array}$} & \multirow{2}{*}{$\begin{array}{l}\text { As opiniões do corpo técnico da secretaria é um critério } \\
\text { utilizado em seu município para o estabelecimento das } \\
\text { prioridades na saúde? }\end{array}$} & Sim \\
\hline & & Não \\
\hline \multirow{3}{*}{$\begin{array}{l}\text { Conselho Municipal } \\
\text { de Saúde }\end{array}$} & \multirow{3}{*}{$\begin{array}{l}\text { Como você avalia a atuação do Conselho Municipal de } \\
\text { Saúde (CMS) atualmente no seu município? }\end{array}$} & Não é atuante \\
\hline & & Atuante \\
\hline & & Parcialmente atuante \\
\hline \multirow[t]{6}{*}{ Participação Social } & \multirow{6}{*}{$\begin{array}{l}\text { Qual a principal forma de participação da comunidade no } \\
\text { Sistema Único de Saúde (SUS)? }\end{array}$} & Intervenção de vereadores \\
\hline & & CMS \\
\hline & & $\begin{array}{l}\text { Associação comercial e } \\
\text { industrial }\end{array}$ \\
\hline & & Não há participação \\
\hline & & Redes Sociais \\
\hline & & Outros \\
\hline \multirow{4}{*}{$\begin{array}{l}\text { Apoio do Conselho } \\
\text { das secretarias } \\
\text { municipais de Saúde } \\
\text { do Rio Grande do } \\
\text { Sul (COSEMS-RS) }\end{array}$} & \multirow{4}{*}{$\begin{array}{l}\text { Qual é o grau de apoio do COSEMS/RS (a nível de } \\
\text { cooperação técnica) para o planejamento e a gestão do seu } \\
\text { município? }\end{array}$} & Não utilizei \\
\hline & & Baixo \\
\hline & & Médio \\
\hline & & Alto \\
\hline $\begin{array}{l}\text { Percentual de } \\
\text { aplicação de recursos } \\
\text { municipais em saúde }\end{array}$ & $\begin{array}{l}\text { Considerando a Emenda Constitucional-29, qual } \\
\text { o percentual médio da arrecadação de impostos e } \\
\text { transferências constitucionais que o seu município } \\
\text { costuma destinar ao custeio de ações e serviços de saúde? }\end{array}$ & $\begin{array}{l}\text { Podendo ser atribuído } \\
\text { qualquer valor entre } 15 \\
\text { e } 40 \%\end{array}$ \\
\hline \multirow{4}{*}{$\begin{array}{l}\text { Quanto a Lei de } \\
\text { Responsabilidade } \\
\text { Fiscal limita a } \\
\text { autonomia de } 0 \text { a } 10\end{array}$} & \multirow{4}{*}{$\begin{array}{l}\text { De } 0 \text { a 10, quanto a Lei de Responsabilidade Fiscal limita a } \\
\text { sua autonomia de gestão? }\end{array}$} & 0- Não limita \\
\hline & & 1 a 4 - Limita pouco \\
\hline & & 5 a 7 - Limita parcialmente \\
\hline & & 8 a 10 - Limita muito \\
\hline \multirow{5}{*}{$\begin{array}{l}\text { Grau de dificuldade } \\
\text { de executar a gestão } \\
\text { municipal da saúde }\end{array}$} & $\begin{array}{l}\text { Indique qual o grau de dificuldade para administrar a sua } \\
\text { secretaria de saúde hoje em relação a: }\end{array}$ & $\begin{array}{l}\text { Todas tendo como } \\
\text { respostas possíveis: }\end{array}$ \\
\hline & \multirow{4}{*}{$\begin{array}{l}\text { i) pouco conhecimento do gestor; } \\
\text { ii) falta de comprometimento dos profissionais de saúde; } \\
\text { iii) disponibilidade de recursos financeiros; } \\
\text { iv) rotatividade de profissionais; } \\
\text { v) profissionais resistentes a mudanças. }\end{array}$} & Nenhuma \\
\hline & & Baixa \\
\hline & & Média \\
\hline & & Alta \\
\hline
\end{tabular}

Fonte: Elaboração dos autores, 2018.

a função foi referida por 93,9\% dos secretários. Com relação ao tempo de vinculação no cargo, na atual gestão, 147 (55,7\%) estava há menos de um ano (Tabela 1 ). 
Tabela 1. Distribuição de frequência das variáveis descritivas apresentadas através de valores absolutos (n) e respectivas porcentagens (\%) quanto ao perfil do gestor e características dos municípios segundo condição referida por 264 Secretários Municipais de Saúde que atuavam em municípios do estado do Rio Grande do Sul (RS) no ano de 2017.

\begin{tabular}{|c|c|c|}
\hline Variáveis & Categorias & $\mathbf{n}^{*}(\%)$ \\
\hline \multirow[t]{4}{*}{ Grau de Escolaridade } & Fundamental completo, médio e técnico incompletos & $11(4,2)$ \\
\hline & Médio e téc. completo & $54(20,5)$ \\
\hline & Superior incompleto & $30(11,4)$ \\
\hline & Superior completo & $169(63,9)$ \\
\hline \multirow[t]{16}{*}{ Profissão } & Administrador & $40(15,2)$ \\
\hline & Enfermeiro & $33(12,5)$ \\
\hline & Tec. saúde: enfermagem, radiologia e química & $23(8,0)$ \\
\hline & Professor Pedagogo Ed. Físico & $22(8,3)$ \\
\hline & $\begin{array}{l}\text { Out. prof. saúde: Cir. dentista, Veterinário, Nutricionista, } \\
\text { Fonoaudiologia, Farmácia, Biomedicina }\end{array}$ & $17(6,4)$ \\
\hline & Contador & $15(5,7)$ \\
\hline & Agricultor & $12(4,5)$ \\
\hline & Motorista Operador de máquina Condutor de ambulância & $10(3,8)$ \\
\hline & Assistente Social & $7(2,7)$ \\
\hline & Biólogo ou Gestão Ambiental & $7(2,7)$ \\
\hline & Advogado & $6(2,3)$ \\
\hline & Comerciante ou Rep. Comercial & $6(2,3)$ \\
\hline & Psicólogo & $6(2,3)$ \\
\hline & Fisioterapeuta & $5(1,9)$ \\
\hline & Médico & $5(1,9)$ \\
\hline & Outros & $50(18,9)$ \\
\hline \multirow{4}{*}{$\begin{array}{l}\text { Tempo de Secretário de } \\
\text { Saúde na atual gestão }\end{array}$} & Menos de um ano & $147(55,7)$ \\
\hline & Mais de um ano & $20(7,6)$ \\
\hline & Mais de dois anos & $17(6,4)$ \\
\hline & Mais de três anos & $80(30,3)$ \\
\hline \multirow{2}{*}{$\begin{array}{l}\text { Já foi Secretário de } \\
\text { Saúde em outras gestões }\end{array}$} & Já foi antes & $103(39,0)$ \\
\hline & Não foi & $161(61,0)$ \\
\hline \multirow{2}{*}{$\begin{array}{l}\text { Ser filiado a um partido } \\
\text { político }\end{array}$} & Sim & $210(79,5)$ \\
\hline & Não & $54(20,5)$ \\
\hline \multirow{6}{*}{$\begin{array}{l}\text { População estimada do } \\
\text { município em que é } \\
\text { Secretário de Saúde }\end{array}$} & Até 5.000 hab. & $115(43,6)$ \\
\hline & De 5.001 a 10.000 hab. & $58(22,0)$ \\
\hline & De 10.001 a 20.000 hab. & $38(14,4)$ \\
\hline & De 20.001 a 50.000 hab. & $26(9,8)$ \\
\hline & De. 50.001 a 100.000 hab. & $17(6,4)$ \\
\hline & De 100.001 a 500.000 hab. & $10(3,8)$ \\
\hline \multirow{4}{*}{$\begin{array}{l}\text { Habilitação do } \\
\text { Município }\end{array}$} & Gestão Plena de Saúde & $36(13,6)$ \\
\hline & Gestão Plena de Atenção Básica & $196(74,2)$ \\
\hline & Não sei & $18(6,8)$ \\
\hline & Não respondeu & $14(5,3)$ \\
\hline
\end{tabular}

${ }^{*} \mathrm{n}(\%)$ = número absoluto/porcentagem.

Fonte: Elaboração dos autores, 2018.

Os municípios eram $79,9 \%$ de pequeno porte (até 20.000 habitantes) segundo condição referida pelo gestor, bem como, a maioria referiu habilitação na modalidade de Gestão Plena de Atenção Básica (Tabela 2).
Em relação à gestão, quanto à atuação do Conselho Municipal de Saúde (CMS), 130 referiram como parcialmente atuante, 122 como atuantes e 12 como não atuantes. Quanto à forma que os munícipios exercem na participação 
social, a maioria (181) referiu-se ao CMS como principal forma de participação, seguido das redes sociais, contudo, 14 indivíduos referiram que não há participação da comunidade na gestão de seus municípios.

Os gestores referiram que a maioria aderiu aos programas Mais Médicos e PMAQ. A média de gastos segundo relatos foi de aproximadamente $20,0 \%$ das receitas brutas do município (Tabela 2).

A análise da diferença entre médias tendo o porte populacional categorizado como variável explicativa mostrou que há diferenças significativas no perfil do gestor e nas características da ges-

Tabela 2. Distribuição de frequência ou medidas de tendência central e dispersão de variáveis categóricas ou contínuas quanto a aspectos relativos a gestão, segundo condição referida por 264 Secretários Municipais de Saúde que atuavam em municípios do estado do Rio Grande do Sul (RS) no ano de 2017.

\begin{tabular}{|c|c|c|}
\hline Variáveis & Categorias & $\begin{array}{c}\mathbf{n}(\%)^{\star} / \\
\text { Média }( \pm \mathrm{DP})\end{array}$ \\
\hline \multirow{3}{*}{$\begin{array}{l}\text { Existem médicos dos Programa Mais Médicos atuando no } \\
\text { município }\end{array}$} & Sim & $195(73,9)$ \\
\hline & Não & $54(20,5)$ \\
\hline & Não respondeu & $15(5,7)$ \\
\hline \multirow{4}{*}{$\begin{array}{l}\text { Município participa do Programa Nacional de Melhoria do } \\
\text { Acesso e Qualidade da Atenção Básica PMAQ-AB }\end{array}$} & Todas as equipes & $161(61,0)$ \\
\hline & Algumas equipes & $45(17,0)$ \\
\hline & Nenhuma equipe & $23(8,7)$ \\
\hline & Não respondeu & $35(13,3)$ \\
\hline \multirow{5}{*}{$\begin{array}{l}\text { Apoio das instituições para o planejamento e a gestão: } \\
\text { COSEMS-RS }\end{array}$} & Não utilizei & $17(6,4)$ \\
\hline & Baixo & $38(14,4)$ \\
\hline & Médio & $125(47,3)$ \\
\hline & Alto & $66(25,0)$ \\
\hline & Não respondeu & $18(6,8)$ \\
\hline \multicolumn{2}{|l|}{ Percentual de aplicação de recursos municipais em saúde } & $19,80(3,39)$ \\
\hline \multicolumn{2}{|l|}{$\begin{array}{l}\text { Quanto a Lei de Responsabilidade Fiscal limita a autonomia } \\
\text { de } 0 \text { a } 10\end{array}$} & $6,64(3,11)$ \\
\hline \multirow{2}{*}{$\begin{array}{l}\text { Critério utilizado para estabelecer as prioridades na saúde: } \\
\text { Demanda espontânea }\end{array}$} & $\operatorname{Sim}$ & $179(67,8)$ \\
\hline & Não & $85(32,2)$ \\
\hline \multirow{2}{*}{$\begin{array}{l}\text { Critério utilizado para estabelecer as prioridades na saúde: } \\
\text { Parecer do corpo técnico. }\end{array}$} & Sim & $143(54,2)$ \\
\hline & Não & $121(45,8)$ \\
\hline \multirow{3}{*}{$\begin{array}{l}\text { Grau de dificuldades administrar a secretaria pouco } \\
\text { conhecimento do Gestor }(n=261)^{* *}\end{array}$} & Nenhuma ou baixa & $157(60,2)$ \\
\hline & Média ou alta & $89(34,1)$ \\
\hline & Não respondeu & $15(5,7)$ \\
\hline \multirow{3}{*}{$\begin{array}{l}\text { Grau de dificuldade de administrar a secretaria devido à falta } \\
\text { de comprometimento dos Profissionais de saúde }\end{array}$} & Nenhuma ou baixa & $133(50,4)$ \\
\hline & Média ou alta & $111(42,0)$ \\
\hline & Não respondeu & $20(7,6)$ \\
\hline \multirow{3}{*}{$\begin{array}{l}\text { Grau de dificuldade de administrar a secretaria pela } \\
\text { disponibilidade de recursos financeiros }\end{array}$} & Nenhuma ou baixa & $49(18,6)$ \\
\hline & Média ou alta & $193(73,1)$ \\
\hline & Não respondeu & $22(8,3)$ \\
\hline \multirow{3}{*}{$\begin{array}{l}\text { Grau de dificuldade de administrar a secretaria rotatividade } \\
\text { de profissionais. }\end{array}$} & Nenhuma ou baixa & $159(60,2)$ \\
\hline & Média ou alta & $82(31,1)$ \\
\hline & Não respondeu & $23(8,7)$ \\
\hline \multirow{3}{*}{$\begin{array}{l}\text { Grau de dificuldade de administrar a secretaria profissionais } \\
\text { resistentes a mudanças }\end{array}$} & Nenhuma ou baixa & $117(44,3)$ \\
\hline & Média ou alta & $124(47,0)$ \\
\hline & Não respondeu & $23(8,7)$ \\
\hline \multirow[t]{4}{*}{ Modelo de Atenção Básica no Município } & ESF & $132(50,0)$ \\
\hline & ESF e outros & $108(40,9)$ \\
\hline & Outro modelo & $10(3,8)$ \\
\hline & Não respondeu & $14(5,3)$ \\
\hline
\end{tabular}

"n (\%) = número absoluto/porcentagem. DP = Desvio Padrão. ${ }^{* *}$ Variável com um " $n$ " menor por ausência de informações.

Fonte: Elaboração dos autores, 2018. 
tão quando o tamanho do município é levado em consideração. Observou-se uma maioria significativa de secretárias nos municípios de pequeno porte, contudo, o mesmo não ocorre quando comparado aos municípios de médio e grande porte. Nestes, homens e mulheres dividem o cargo em número muito semelhante. Na tomada de decisão, a demanda espontânea é significativamente considerada uma prioridade para os pequenos municípios, enquanto o parecer do corpo técnico toma mais expressão à medida que o porte dos municípios aumenta (Tabela 3).

No cruzamento das variáveis dependentes com o porte populacional dicotomizado, observou-se diferenças estatisticamente significativas entre os municípios que receberam profissionais oriundos do programa Mais Médicos. Sendo que dentre a totalidade dos municípios de menos de 10.000 habitantes houve mais municípios descobertos pelo programa quando comparados aos municípios maiores. No mesmo sentido, foi possível observar que nos municípios pequenos houve significativamente mais equipes que aderiram ao programa PMAQ (Tabela 4).

Houve uma diferença significativa em relação a variável que aferia o quanto a Lei de Responsabilidade Fiscal limitava os processos de gestão municipal da saúde, com um número maior de secretários de municípios maiores reportando que tal lei constitui uma barreira que limita muito a gestão (Tabela 4).

Os secretários também descreveram de forma significativamente diferente questões relacionadas com o grau de dificuldade de administrar a secretaria devido à falta de comprometimento e a resistência a mudanças dos profissionais de saúde, onde se observou que tais aspectos representavam um problema maior para os municípios de médio e grande porte quando comparado aos pequenos (Tabela 4).

\section{Discussão}

A pesquisa tem caráter inédito principalmente com relação à abrangência do cenário do estudo uma vez que conseguiu atingir um número expressivo de secretários(as) municipais de saúde, tendo representadas todas as coordenadorias e regiões de saúde do estado do Rio Grande do Sul. Além disso, este estudo mostrou-se capaz de responder ao objetivo previamente estabelecido uma vez que permitiu conhecer quem eram e como atuavam os(as) gestores(as) municipais de saúde no estado do Rio Grande do Sul no período estudado.

Tabela 3. Diferenças entre médias das variáveis dependentes em relação a variável independente, no caso, o porte populacional dos municípios do estado do Rio Grande do Sul que foi categorizado para fins de análise. $\mathrm{N}=264$ Secretários Municipais de Saúde que atuavam em municípios do estado do Rio Grande do Sul (RS) no ano de 2017.

\begin{tabular}{|c|c|c|c|c|c|}
\hline \multirow{2}{*}{ Variáveis } & \multirow{2}{*}{ Categorias } & $\leq 10.000$ & $10.001-20.000$ & \multicolumn{2}{|l|}{$20.001-500.000$} \\
\hline & & n (\%) & n $(\%)$ & n $(\%)$ & p-valor \\
\hline \multirow[t]{2}{*}{ Sexo } & Feminino & $109(63,0)$ & $18(47,4)$ & $26(49,1)$ & 0,07 \\
\hline & Masculino & $64(37,0)$ & $20(52,6)$ & $27(50,9)$ & \\
\hline \multirow{2}{*}{$\begin{array}{l}\text { Critério utilizado para estabelecer } \\
\text { as prioridades na saúde: Demanda } \\
\text { espontânea }\end{array}$} & Sim & $125(72,3)$ & $27(71,1)$ & $27(50,9)$ & $0,01^{\star}$ \\
\hline & Não & $48(27,7)$ & $11(28,9)$ & $26(49,1)$ & \\
\hline \multirow{2}{*}{$\begin{array}{l}\text { Critério utilizado para estabelecer as } \\
\text { prioridades na saúde: Parecer técnico }\end{array}$} & Sim & $82(47,4)$ & $24(63,2)$ & $37(69,8)$ & $0,00^{\star}$ \\
\hline & Não & $91(52,6)$ & $14(36,8)$ & $16(30,2)$ & \\
\hline \multirow[t]{2}{*}{ Habilitação do Município $^{* *}(\mathrm{n}=232)$} & $\begin{array}{l}\text { Gestão Plena de } \\
\text { Saúde. }\end{array}$ & $15(9,9)$ & $7(21,2)$ & $14(29,2)$ & $0,00^{*}$ \\
\hline & $\begin{array}{l}\text { Gestão Plena de } \\
\text { Atenção Básica } \\
\text { de Saúde }\end{array}$ & $136(90,1)$ & $26(78,8)$ & $34(70,8)$ & \\
\hline \multirow{2}{*}{$\begin{array}{l}\text { Modelo de Atenção Básica no } \\
\text { Município }^{\star *}(\mathrm{n}=250)\end{array}$} & ESF & $98(59,8)$ & $21(60,0)$ & $13(25,5)$ & $0,00^{\star}$ \\
\hline & $\begin{array}{l}\text { ESF/Misto e } \\
\text { outros modelos } \\
\text { de } \mathrm{AB}\end{array}$ & $66(40,2)$ & $14(40,0)$ & $38(74,5)$ & \\
\hline
\end{tabular}

\footnotetext{
* Foram considerados significativos os valores de $\mathrm{p}<0,05 .{ }^{\star *}$ Variáveis com um "n" menor por ausência de informações.
} Fonte: Elaboração dos autores, 2018. 
Tabela 4. Diferenças entre médias das variáveis dependentes em relação a variável independente, no caso, o porte populacional dos municípios do estado do Rio Grande do Sul que foi dicotomizada para esta análise. $\mathrm{N}=264$ Secretários Municipais de Saúde que atuavam em municípios do estado do Rio Grande do Sul (RS) no ano de 2017.

\begin{tabular}{|c|c|c|c|c|}
\hline Variáveis & Categorias & $\leq 10.000 \mathrm{n}(\%)$ & $>10.000 \mathrm{n}(\%)$ & p-valor \\
\hline \multirow{2}{*}{$\begin{array}{l}\text { Existem Médicos do Programa Mais Médicos } \\
\text { no Município } \\
\star * * \\
(n=249)\end{array}$} & Sim & $116(70,7)$ & $79(92,9)$ & $0,00^{*}$ \\
\hline & Não & $48(29,3)$ & $6(7,1)$ & \\
\hline \multirow{4}{*}{$\begin{array}{l}\text { Município participa do Programa Nacional } \\
\text { de Melhoria do Acesso e Qualidade da } \\
\text { Atenção Básica PMAQ-AB }\end{array}$} & Todas & $114(65,9)$ & $47(51,6)$ & $0,00^{*}$ \\
\hline & Algumas & $18(10,4)$ & $27(29,7)$ & \\
\hline & Nenhuma & $18(10,4)$ & $5(5,5)$ & \\
\hline & Não respondeu & $23(13,3)$ & $12(13,2)$ & \\
\hline \multirow[t]{2}{*}{ Você é filiado a um Partido Político } & Sim & $142(82,1)$ & $68(74,7)$ & 0,15 \\
\hline & Não & $31(17,9)$ & $23(25,3)$ & \\
\hline \multirow{4}{*}{$\begin{array}{l}\text { Percentual de aplicação de recursos } \\
\text { municipais em saúde }\end{array}$} & De 15 a $17 \%$ & $42(28,0)$ & $17(21,3)$ & 0,57 \\
\hline & De 18 a $20 \%$ & $57(38,0)$ & $37(46,3)$ & \\
\hline & De 21 a $22 \%$ & $22(14,7)$ & $10(12,4)$ & \\
\hline & De 23 a $32 \%$ & $29(19,3)$ & $16(20,0)$ & \\
\hline \multirow[t]{3}{*}{ Lei de Responsabilidade Fiscal ${ }^{\star \star}(n=229)$} & Limita pouco & $37(24,7)$ & $8(10,1)$ & 0,01 \\
\hline & Limita médio & $48(32,0)$ & $23(29,1)$ & \\
\hline & Limita muito & $65(43,3)$ & $48(68,8)$ & \\
\hline \multirow{2}{*}{$\begin{array}{l}\text { Grau de dificuldades pouco conhecimento } \\
\text { do Gestor }\end{array}$} & Média e alta & $62(38,5)$ & $27(31,8)$ & 0,29 \\
\hline & Nenhuma ou Baixa & $99(61,5)$ & $58(68,2)$ & \\
\hline \multirow{2}{*}{$\begin{array}{l}\text { Grau de dificuldade de administrar a } \\
\text { secretaria devido à falta de comprometimento } \\
\text { dos Profissionais de saúde }\end{array}$} & Média e alta & $64(40,3)$ & $47(55,3)$ & $0,02^{*}$ \\
\hline & Nenhuma ou Baixa & $95(59,7)$ & $38(44,7)$ & \\
\hline \multirow{2}{*}{$\begin{array}{l}\text { Grau de dificuldade de administrar a } \\
\text { secretaria pela disponibilidade de recursos } \\
\text { financeiros }^{\star *}(n=242)\end{array}$} & Média e alta & $122(77,2)$ & $71(84,5)$ & 0,17 \\
\hline & Nenhuma ou Baixa & $36(22,8)$ & $13(15,5)$ & \\
\hline \multirow{2}{*}{$\begin{array}{l}\text { Grau de dificuldade de administrar a secretaria } \\
\text { rotatividade de profissionais }{ }^{\star *}(\mathrm{n}=241)\end{array}$} & Média e alta & $52(32,9)$ & $30(36,1)$ & 0,61 \\
\hline & Nenhuma ou Baixa & $106(67,1)$ & $53(63,9)$ & \\
\hline \multirow{2}{*}{$\begin{array}{l}\text { Grau de dificuldade de administrar a secretaria } \\
\text { profissionais resistentes a mudanças }\end{array}$} & Média e alta & $70(44,0)$ & $54(65,9)$ & $0,00^{*}$ \\
\hline & Nenhuma ou Baixa & $89(56,0)$ & $28(34,1)$ & \\
\hline
\end{tabular}

${ }^{*}$ Foram considerados significativos os valores de $\mathrm{p}<0,05$. ${ }^{*}$ Variáveis com um "n" menor por ausência de informações. Fonte: Elaboração dos autores, 2018.

O índice de retorno obtido neste estudo $(59,8 \%)$ foi maior do que o encontrado em outras pesquisas de igual interesse, sendo, uma realizada no estado do Mato Grosso $(52,5 \%)^{8} \mathrm{e}$ outra realizada em Minas Gerais $(40,0 \%)^{10}$. Há evidência de que a taxa de retorno padrão de pesquisas feitas por meio de correio eletrônico é comparável àquelas obtidas via modo postal variando entre sete a $13,0 \%$ e que, de modo geral, a ativação da pesquisa pelos respondentes pode estar relacionada com o interesse de tais atores sobre o objeto da pesquisa ${ }^{11}$. Desta forma, acredita-se que é possível que os secretários que participaram possam ter interesse em compartilhar e compreender coletivamente os processos de gestão municipal da saúde.
Percebem-se diferenças no perfil dos secretários municipais de saúde em relação a outros estudos principalmente quanto ao sexo e a escolaridade $^{12}$. Os resultados apontaram para a tendência crescente da presença feminina na gestão do SUS. Tal fato já vem sendo observado há alguns anos com crescimento progressivo ${ }^{8,13,14}$. Contudo, quando feita análise considerando o porte populacional, observou-se que a presença feminina mais expressiva está dada em municípios de pequeno porte, e, embora, não se possa desconsiderar a representatividade igualitária encontrada em municípios maiores, ainda observase através da literatura que há pouca expressividade, e desvalorização sofrida pelas mulheres no âmbito da gestão ${ }^{15}$. 
A média de idade encontrada foi ligeiramente maior do que a de outros estudos realizados com secretários de estado ${ }^{16,17}$. Este estudo apresentou um percentual de nível de escolaridade superior completo que concorda com o estudo de Ohira et al. $^{18}$, porém, supera resultados encontrados por Pinafo et al. ${ }^{17}$, em uma pesquisa realizada com gestores de municípios de semelhante porte populacional. Contudo, ficou aquém tanto da pesquisa nacional de Fleury et al. ${ }^{13}$ quanto à realizada em âmbito municipal por Garózi ${ }^{14}$.

Com relação à profissão dos gestores, a maioria dos participantes desta pesquisa foi composta por administradores(as) e enfermeiros(as), sendo que houve uma pequena representatividade de médicos(as), o que diverge de perfil de formação encontrado por Fleury et al. ${ }^{13}$ e do que encontrou Moura et al. ${ }^{19}$ em 2016. O motivo de tal discordância é desconhecido, porém, pode-se especular que esteja relacionada com o porte populacional dos municípios da maioria dos respondentes, uma vez que se observa uma dificuldade de fixação do profissional médico até mesmo para a assistência em municípios de pequeno porte.

Tal fato pode ser considerado importante quando se trata de quebra do modelo hegemônico presente na área da saúde, uma vez que, quando somados os gestores formados nas diferentes áreas da saúde, o índice se aproxima do estudo de Ferreto et al..$^{20}$ que encontrou um número próximo de profissionais da área da saúde atuando na gestão. Porém, embora as reformas de diretrizes curriculares instituídas na primeira década de 2000 para todos os cursos da saúde preconizem a formação de competências e habilidades relacionadas com a gestão pública da saúde, o percentual encontrado de profissionais com formação na área mostrou-se pequena quando comparada com um estudo realizado em 2016 por Castro e Souza $^{16}$ na gestão municipal da educação que encontrou uma totalidade de gestores educadores ${ }^{16}$.

Cabe pensar nos desafios que estão postos para os gestores do SUS, uma vez que a sua prática cotidiana é permeada por constantes mudanças da legislação da saúde, diferentes interesses, diferentes espaços de negociação e decisão, formais e informais e pelas crescentes demandas. Desta forma, há uma necessidade de constantes mudanças no modelo de atenção à saúde e consequentemente de preparo destes gestores ${ }^{21}$. Autores referem que a gestão vai além de gerenciar "coisas", sendo indispensável a visão estratégica de gestão nos diversos âmbitos de negociações para a viabilização da atenção à saúde de forma custo efetiva. As tarefas desempenhadas por eles se desenvolvem em dimensões "políticas, técnicas e administrativas"17,22,23.

Com relação à dimensão política cabe pensar na interlocução dos gestores com a sociedade civil, onde deveria haver consolidação e legitimidade de participação por meio dos Conselhos de Saúde, legalmente instituídos pela Lei $8.142 / 90^{24}$. Tais conselhos existem e funcionam na maioria dos municípios, porém os resultados deste estudo mostram que ainda há fragilidade na gestão participativa do sistema, uma vez que alguns gestores referiram que a participação da sociedade civil é inexistente em suas gestões. É possível que as limitações de legitimidade e de atuação dos conselhos sejam decorrentes do grau de organização da sociedade civil, de problemas intrínsecos dos mecanismos representativos de participação e das práticas políticas dominantes no país ${ }^{25}$.

Outro aspecto que permeia a gestão democrática é o diálogo entre gestão e trabalhadores. Por um lado, as questões de gestão de pessoas e da formação de trabalhadores para o SUS constituem uma inquietação e um descontentamento já estabelecido há um bom tempo ${ }^{26,27}$. Passaram-se quase 30 anos da construção do sistema, o país encaminha-se para a segunda etapa de reformas curriculares ${ }^{28}$, contudo, é na impessoalidade de um município de maior porte que as lacunas na formação de profissionais de saúde mostram-se problemáticas para a gestão municipal do SUS $8,29,30$. Por outro, o distanciamento e a impessoalidade estabelecidos, entre a gestão da saúde de grandes munícipios e seus trabalhadores também parece determinar a constituição de barreiras que dificultam a otimização dos processos de trabalho e de melhores práticas ${ }^{31}$. Estudos relatam que a gestão de pessoas vem sendo considerada uma questão complexa para a gestão ${ }^{8,12,30}$.

O estudo apresentou um percentual expressivo de gestores filiados a partidos políticos. Sendo que em números absolutos, os resultados encontrados nesta pesquisa, em relação à filiação, superaram os encontrados no estudo de Fleury et al. ${ }^{13}$. Junqueira et al. ${ }^{12}$ em 2010, consideraram necessário ampliar a discussão sobre a inserção, na gestão pública, de profissionais técnicos que refutem o clientelismo, evidente, por exemplo, na indicação política para a ocupação de cargos de gestor de saúde, aspectos que são, segundo tais autores, mais facilmente observados nos municípios de pequeno porte.

Em relação ao exercício dos(as) secretários(as) na função, os achados desta pesquisa mostraram que praticamente metade destes ocu- 
pava o cargo a menos de um ano na atual gestão. Porém, muitos secretários já haviam ocupado a pasta em outras gestões. Tais resultados se aproximam do estudo de Luna que também mostra a intermitência da ocupação deste cargo ${ }^{8}$. No entanto, faz-se necessário contextualizar o período em que aconteceu a coleta, próximo ao período eleitoral, em que muitos gestores se afastam para concorrer a outros cargos políticos.

A gestão municipal perpassa uma complexa rotina administrativa, com múltiplas atribuições práticas, tanto no que se refere à micropolítica quanto às demandas burocráticas. As atribuições burocráticas somam-se diariamente e o apoio e a troca de experiências entre os gestores são fundamentais, sendo que, arenas tais como reuniões e congressos convocados pelo Conselho de Secretarias Municipais de Saúde são fóruns que apoiam a construção de políticas e que aproximam esferas e atores envolvidos na gestão da saúde $^{32}$. Neste estudo, poucos foram os gestores que referiram não fazer uso do COSEMS-RS como instituição de apoio para o planejamento e a gestão, corroborando a consecução do papel proposto por tal conselho.

A média de gastos com serviços de saúde segue estudo paranaense ${ }^{20}$ que já demonstrou que os munícipios investem em saúde mais do que o percentual exigido. A responsabilidade pelo financiamento da saúde deve ser compartilhada pelas três esferas de governo, contudo, observase que os municípios estão aplicando recursos cada vez maiores devido à dificuldade de assumir a gestão plena da atenção básica, e do sistema, frente ao descumprimento ou cumprimento parcial do que é o estabelecido para estados e união. Há uma luta histórica visando o adequado financiamento para este sistema que se propõem a ser universal e integral e que por fim, onera os municípios. Alguns estados inclusive incluíram indevidamente como despesas em ações e serviços de saúde os gastos com pensionistas, saneamento, moradia, alimentação de escolares e presos, entre outros. Além disso, observou-se enorme resistência por parte do Governo Federal em garantir a regulamentação que tinha o compromisso de destinar mais recursos para a área da saúde ${ }^{33-36}$.

A gestão da saúde também é interdependente e parece ser determinada sob alguns aspectos pelo tamanho do município onde o secretário de saúde atua. Observou-se que os municípios de menor porte optaram pela Gestão Plena de Atenção Básica e que as secretarias organizam o cuidado de atenção básica do município, elegendo, em sua maioria, como modelo de atenção, a
Estratégia da Saúde da Família (ESF). Esta tem sido a tendência, o que já foi observado em outros estudos ${ }^{8,13,20}$.

Tais evidências mostram que esta estratégia de organização da atenção básica tem por objetivo geral a reorientação do modelo assistencial, tornando este nível de atenção a principal porta de entrada do sistema e o nível de atenção ordenador da rede de atenção e da coordenação do cuidado $^{37}$.

A organização da atenção básica e a viabilidade de execução da ESF também parecem ser diferentes conforme o tamanho do município. $O$ resultado encontrado neste estudo respalda a recorrente queixa dos gestores com relação à fixação do profissional médico ${ }^{8,38}$ em municípios menores e mais afastados dos grandes centros ${ }^{10}$. Foi possível observar que alguns pequenos municípios não tinham recebido profissionais do Programa Mais Médicos (PMM), o que sugere mais estudos sobre quais as dificuldades que se relacionam com a fixação deste profissional em municípios de pequeno porte. Outrossim, as limitações em relação à adesão aos programas propostos pelo Ministério da Saúde parecem não se esgotar no PMM, sendo que foi possível observar diferenças entre médias estatisticamente significativas em relação ao número de municípios pequenos que não possuíam nenhuma equipe vinculada ao Programa de melhoria do acesso e da qualidade da atenção básica (PMAQ-AB), seguindo resultados encontrados por Pinto et al. ${ }^{39}$ em 2012.

Neste ínterim, cabe pensar na influência da Lei de Responsabilidade Fiscal sobre o provimento de ações e serviços de saúde e na fixação dos profissionais. Historicamente os gestores e pesquisadores vêm apontando o impacto da lei neste setor, uma vez que ela limita as despesas com pessoal em um cenário que exige uma ampla gama de trabalhadores para prover por assistência integral e universal à saúde ${ }^{40}$. Os autores relatam que os gestores lançam mão de manobras para adequar-se aos limites de despesas para evitar a aplicação das sanções fiscais, que vão desde a terceirização de pessoal de atividades-meio, diminuição de cargos até a exclusão dos contratos precários no cálculo de despesas com pessoal dos municípios. É possível que significativamente mais gestores de municípios médios e grandes tenham referido que a LRF impacta muito na gestão municipal porque as demandas saúde/trabalhadores são diretamente proporcionais ao número de habitantes. Contudo, cabe destacar que a queixa de que a LRF limita muito a capacidade 
de gestão foi observada neste estudo na fala da maioria dos gestores, independente do porte do município. Tais achados demonstram concretamente a necessidade de mais estudos, já apontada na literatura ${ }^{41}$, sobre os efeitos da LRF na gestão municipal da saúde, uma vez que o uso de táticas que mascaram a realidade pode distorcer a real condição dos municípios, refletindo-se numa fragilidade na qualidade das pesquisas que vêm sendo realizadas.

O financiamento, como já foi dito, também é outro tópico que possui um peso muito grande na gestão municipal, observa-se que os municípios em sua maioria precisam despender gastos maiores do que o previsto em lei e referem que este aspecto representa uma dificuldade na maioria dos municípios ${ }^{40}$. Os gastos municipais além do previsto são realidade no Brasil ${ }^{8,20}$. Araújo et al. ${ }^{42}$ analisaram a destinação dos recursos e encontraram diferenças significativas tanto na quantidade de gastos per capta em saúde, quanto na destinação dos recursos financeiros.

A queda da participação dos recursos federais no financiamento da saúde pública reduz o papel exercido pelo governo federal na determinação da política de saúde e aumenta a responsabilidade dos municípios ${ }^{8,20}$, o que justifica o aumento crescente da preocupação dos gestores municipais ${ }^{43}$. Este fato tende ao agravamento considerando a promulgação da Emenda Constitucional no 95 que congelou os gastos com saúde por 20 anos e estabeleceu limites desfavoráveis de correção no financiamento da saúde $e^{44-46}$.

Contudo, cabe ressaltar que o financiamento isoladamente não é condição para o sucesso na gestão e na atenção à saúde da população. Queiros et al. ${ }^{47}$ em seu estudo referiu que a adequação de recursos financeiros é uma condição necessária, todavia não suficiente, para alcançar a eficiência nos indicadores de saúde de um município. Isto faz sentido quando observamos as dificuldades relatadas pelos gestores principalmente nos municípios de médio e grande porte que reportaram que a falta de comprometimento e a resistência dos profissionais a mudanças representam uma dificuldade média ou alta para a gestão da atenção da saúde. Neste contexto é preciso pensar na micropolítica do trabalho e nas redes que se constroem cotidianamente nos serviços de saúde, uma vez que o trabalho em saúde se produz a partir de encontros e de troca de afetos. Franco já em 2006 referia que este processo traz a ideia de pertença, isto é, os trabalhadores pertencem uns aos outros, a suas equipes e a uma rede maior que faz fluxos-conectivos com outras equipes e unidades de saúde e que têm suas conexões expandidas para o território e, por conseguinte do município ${ }^{48}$. Logo, é passível de especulação pensar no quanto há mais distância e barreiras entre os trabalhadores e a gestão nos grandes municípios do que nos pequenos.

Comprometimento e abertura para mudanças implicam em responsabilização e disponibilidade dos trabalhadores e podem ser um trunfo ou um problema para os gestores. Mas, para que isso possa ser cobrado do profissional é preciso que ele possua outras coisas para além de apenas competências e habilidades técnicas. Maissiat et al. ${ }^{49}$ em um estudo feito junto a trabalhadores da atenção básica na cidade de Porto Alegre e região metropolitana relataram a importância do reconhecimento profissional, da liberdade de expressão, bem como, da liberdade para negociar com as chefias como características fundamentais para a realização profissional. No estudo também há um destaque que pode explicar as limitações que os gestores apontaram em relação aos seus trabalhadores em municípios maiores, os autores observaram que a liberdade de expressão promoveu prazer aos trabalhadores, porém, o aspecto "liberdade com a chefia para negociar o que precisa” foi considerado crítico ${ }^{49}$, o que leva a pensar que mesmo que os trabalhadores tenham a liberdade em suas equipes, podem não ter essa mesma liberdade para negociarem com as chefias e nem mesmo o reconhecimento por não terem a mesma proximidade que os profissionais de pequenos municípios têm em relação aos seus gestores.

\section{Conclusão}

Através do presente estudo, que contou com o empenho e com a solidária participação de praticamente 300 secretários de saúde que se mostraram comprometidos e implicados com a produção de ciência que dê voz e visibilidade a este coletivo e seus cotidianos, foi possível compor um agregado de informações que possibilitou suprir a carência de referências sobre esse ator social para gestão do SUS. A pesquisa teve caráter inédito, visto que não se tem conhecimento de estudo de similar abrangência no estado.

Diante da complexidade da gestão do SUS, e através da descentralização da saúde, é fundamental que o secretário municipal de saúde tenha conhecimento e capacidade de gestão, pois cabe a ele prover os serviços de saúde com efetividade.

O perfil dos gestores municipais, no que tange seu grau de escolaridade e sexo, tem apresentado 
mudanças no decorrer do tempo que foram confirmadas neste estudo. Os resultados mostram que a evolução nas demandas da gestão pode estar elevando o grau de exigência no processo de trabalho do gestor, fato que possivelmente esteja relacionado com a escolaridade dos secretários que em sua maioria tinha curso superior.

Também obtivemos resultados surpreendentes na representatividade feminina no cargo, o que mostra que as mulheres estão, paulatinamente, fazendo-se representar no cenário da gestão pública brasileira. Todavia, este estudo demonstra claramente o quanto este espaço de poder ainda não representa a totalidade dos cidadãos, uma vez que foi observada uma hegemonia branca e que as mulheres fazem-se representar em maior número na gestão de municípios pequenos. Além disso, cabe investigar o quanto a feminilização da gestão da saúde possuirá potencial de mudança nas práticas de gestão em longo prazo.

Diferenças significativas foram encontradas quando o porte populacional do município foi considerado, onde se observou que os pequenos municípios possuíam desvantagens na questão de provimento de médicos, porém, tendo menos dificuldade quando o assunto é a gestão de pessoas.

Por fim, é necessário contextualizar que este estudo possui limitações tais como o seu caráter transversal e o fato de ser representativo apenas para o estado do Rio Grande do Sul. No entanto, consideramos que a realidade deste cenário não seja tão distante dos demais estados no país e que os desafios da gestão municipal do SUS como um todo não sejam muito distintos dos observados nesta pesquisa. Cabe ressaltar um aspecto levantado nesta pesquisa que precisa ser alertado diante do atual cenário político econômico da nação brasileira. A totalidade dos gestores apontou neste estudo o financiamento como uma dificuldade de execução de ações e serviços de saúde e que há um cenário bastante pessimista indicando piora neste quadro o que precisará de união, determinação e resistência por parte dos gestores para que catástrofes sociais possam ser evitadas.

\section{Colaboradores}

JM Arcari trabalhou na concepção, na elaboração da pesquisa e na redação e revisão de todo o texto. APD Barros trabalhou no desenvolvimento da metodologia do instrumento da pesquisa e no manuscrito. RS Rosa trabalhou na concepção do estudo, na análise dos dados e na redação e revisão final do manuscrito. RJ De Marchi trabalhou na construção do instrumento de pesquisa, na análise dos dados e na redação e revisão do manuscrito. AB Martins trabalhou na orientação de todo o desenvolvimento do estudo e na redação do manuscrito. 


\section{Referências}

1. Santos NS. SUS, política pública de Estado: seu desenvolvimento instituído e instituinte e a busca de saídas. Cien Saude Colet 2013; 18(1):273-280.

2. Bodstein R. Atenção básica na agenda da saúde. Cien Saude Colet 2002; 7(3):401-412.

3. Teixeira CF, Molesini JA. Gestão municipal do SUS: atribuições e responsabilidades do gestor do sistema e dos gerentes de unidades de saúde. Rev Baiana Saude Publica 2014; 26(1-2):29.

4. Farah MFS. Parcerias, novos arranjos institucionais e políticas públicas no nível local de governo. Rev Administração Publica 2001; 35(1):119-144.

5. Roese A, Gerhardt TE, Miranda AS. Análise estratégica sobre a organização de rede assistencial especializada em região de saúde do Rio Grande do Sul. Saude Debate 2015; 39(107):935-947.

6. Rio Grande do Sul. Secretaria da Saúde (SES/RS). Plano Estadual de Saúde: 2016/2019. Porto Alegre: SES/ RS; 2016.

7. Rio Grande do Sul. Secretaria da Saúde. Resolução no 555/12 - CIB/RS. Altera a configuração e a quantidade de Regiões de Saúde no Rio Grande do Sul, e institui as Comissões Intergestores Regionais - CIR. Porto Alegre 2012; 19 set.

8. Luna SMM. Perfil dos gestores municipais de saúde do Estado de Mato Grosso. Cáceres [MT]: Ed. Unemat; 2008.

9. Schild VLB. Secretários municipais de saúde no SUS no RS. São Leopoldo: Unisinos; 2006.

10. Souza A. O perfil dos secretários municipais de saúde de Minas Gerais e a organização de programas e projetos municipais. Rev Min Saude Publica 2002; 1(1):110.

11. Freitas HMRD, Janissek-Muniz R, Moscarola J. Uso da Internet no processo de pesquisa e análise de dados. São Paulo: ANEP, 2004.

12. Junqueira TS, Cotta RMM, Gomes RC, Silveira SDFR, Batista RS, Pinheiro TMM, Sampaio RF. As relações laborais no âmbito da municipalização da gestão em saúde e os dilemas da relação expansão/precarização do trabalho no contexto do SUS. Cad Saude Publica 2010; 26(5):918-928.

13. Fleury S, Carvalho AI, Manotas N, Bloch R, Nevares S. Municipalização da saúde e poder local no Brasil. Rev Adm Publica 1997; 31(5):1-15.

14. Garózi DE. Perfil do gestor municipal da saúde e a percepção da Estratégia Saúde da Família-DRS IXMarília-SP [dissertação]. São Paulo: Universidade Estadual Paulista Júlio de Mesquita Filho; 2014.

15. Loureiro P, Cardoso CC. O género e os estereótipos na gestão. Tékhne-Rev Estudos Politécnicos 2008; 10:221238 .

16. Castro MLS, Souza MV. Transformando a gestão da educação municipal da Região Sul: Perspectivas de uma década. Paideia Rev Educación 2016; 46:141-158.

17. Pinafo E, Carvalho BG, Almeida EDFP, Domingos $\mathrm{CM}$, Bonfim MCB. O gestor do sus em município de pequeno porte: perfil, funções e conhecimento sobre os instrumentos de gestão. Rev Saude Publica Paraná 2016; 17(1):130-137.

18. Ohira RHF, Cordoni JRL, Nunes EFPA. Perfil dos gerentes de Atenção Primaria a Saúde de municípios de pequeno porte do norte do Paraná, Brasil. Cien Saude Colet 2014; 19(2):393-400.
19. Moura DCN, Pinto JR, Aragão AEA. Perfil dos profissionais atuantes na gestão em saúde frente ao novo modelo de reorganização do SUS: a regionalização. Tempus Actas Saude Colet 2016; 10(1):75-93.

20. Ferreto LE, Betiatto R, Santanna C, Canterle NMG, Zanamaria N. Administração da saúde pública: o discurso dos gestores da região sudoeste do Paraná. Rev Adm Saude 2007; 9(36):78-84.

21. Savassi LCM. Qualidade em serviços públicos: os desafios da atenção primária. Rev Bra Med Fam Comunidade 2012; 7(23):69-74.

22. Mendes EV. As redes de atenção à saúde. Cien Saude Colet 2010;15(5):2297-2305.

23. Teixeira CF, Molesini JA. Gestão municipal do SUS: atribuições e responsabilidade do gestor do sistema e dos gerentes de unidades de saúde. Rev Baiana Saude Publica 2002; 26(1/2):29-40.

24. Brasil. Conselho Nacional de Saúde (CNS). Lei no 8.142 , de 28 de dezembro de 1990. Dispõe sobre a participação da comunidade na gestão do Sistema Único de Saúde (SUS) e sobre as transferências intergovernamentais de recursos financeiros na área da saúde e dá outras providências. Diário Oficial da União; 1990.

25. Feuerwerker L. Modelos tecnoassistenciais, gestão e organização do trabalho em saúde: nada é indiferente no processo de luta para a consolidação do SUS. Interface (Botucatu) 2005; 9(18):489-506.

26. Ceccim RB, Feuerwerker LCM. O quadrilátero da formação para a área da saúde: ensino, gestão, atenção e controle social. Physis 2004; 14(1):41-65.

27. Merhy EE, Franco TB. Por uma Composição Técnica do Trabalho em saúde centrada no campo relacional e nas tecnologias leves. Apontando mudanças para os modelos tecno-assistenciais. CEBES 2003; 27(65):316-323.

28. Varela DSS, Carvalho MMB, Barbosa MUF, Silva IZF Gadelha RRM, Machado MDFAS. Diretrizes Curriculares Nacionais e a Formação de Profissionais para o SUS. Rev Brasileira Educação Saude 2016; 6(3):39-43.

29. Cavalcanti PCS, Oliveira Neto AV, Sousa MF. Quais são os desafios para a qualificação da Atenção Básica na visão dos gestores municipais? Divulg Saude Debate 2015; 39(105):323-336.

30. Camelo SHH, Angerami ELS. Formação de recursos humanos para a Estratégia de Saúde da Família. Rev Cien Cuidado Saude 2008; 7(1):45-52.

31. Cunha PF, Magajewski F. Gestão participativa e valorização dos trabalhadores: avanços no âmbito do SUS. Saude Soc 2012; 21(1):71-79.

32. Bosio M. COSEMS/RS: 30 anos de história em defesa do SUS. Rev COSEMS RS [periódico na Internet]. 2016 [acessado 2018 Maio 2]; 7(11):7. Disponível em: https://issuu.com/assedisa/docs/160704_revista11_ montada-baixa

33. Brasil. Emenda Constitucional no 29, de 13 de setembro de 2000. Altera os arts. 34, 35, 156, 160, 167 e 198 da Constituição Federal e acrescenta artigo ao Ato das Disposições Constitucionais Transitórias, para assegurar os recursos mínimos para o financiamento das ações e serviços públicos de saúde. Diário Oficial da União 2000; 14 set. 
34. Brasil. Decreto no 7.508, de 28 de junho de 2011. Regulamenta a Lei no 8080 , de 19 de setembro de 1990 , para dispor sobre a organização do Sistema Único de Saúde - SUS, o planejamento da saúde, a assistência à saúde e a articulação interfederativa, e dá outras providências. Diário Oficial da União 2011; 29 jun.

35. Brasil. Lei Complementar $n^{\circ} 141$, de 13 de janeiro de 2012. Regulamenta o $\$ 3^{\circ}$ do art. 198 da Constituição Federal para dispor sobre os valores mínimos a serem aplicados anualmente pela União, Estados, Distrito Federal e Municípios em ações e serviços públicos de saúde; estabelece os critérios de rateio dos recursos de transferências para a saúde e as normas de fiscalização, avaliação e controle das despesas com saúde nas 3 (três) esferas de governo; revoga dispositivos das Leis $\mathrm{n}^{\text {os }} 8.080$, de 19 de setembro de 1990 , e 8.689 , de 27 de julho de 1993; e dá outras providências. Diário Oficial da União 2012; 16 jan.

36. Mendes A, Funcia F. O SUS e seu financiamento. In: Marques RM, Piola SF, Camilo Roa A, organizadores. Sistema de saúde no Brasil: organização e financiamento. Rio de Janeiro: ABRES-MS; 2016. p. 139-168.

37. Brasil. Ministério da Saúde (MS). Política Nacional de Atenção Básica. Brasília: MS; 2012. (Série E. Legislação em Saúde).

38. Mendes JDV, Bittar OJNV. Perspectivas e desafios da gestão pública no SUS. Rev Faculdade Cien Medicas Sorocaba 2014; 16(1):35-39.

39. Pinto HA, Sousa A, Florêncio AR. O Programa Nacional de Melhoria do Acesso e da Qualidade da Atenção Básica: reflexões sobre o seu desenho e processo de implantação. RECIIS 2012; 6(2 Sup.):1-19.

40. Medeiros KR, Tavares RAW. Questões contemporâneas da gestão do trabalho em saúde: em foco a Lei de Responsabilidade Fiscal. Divulg Saude Debate 2012; 47:563-571.

41. Medeiros KR, Albuquerque PC, Tavares RAW, Souza WV. Lei de Responsabilidade Fiscal e as despesas com pessoal da saúde: uma análise da condição dos municípios brasileiros no período de 2004 a 2009. Cien Saude Colet 2017; 22(6):1759-1769.

42. Araújo CEL, Gonçalves GQ, Machado JA. Os municípios brasileiros e os gastos próprios com saúde: algumas associações. Cien Saude Colet 2017; 22(3):953963.
43. Mendes A, Marques RM. O Financiamento da Atenção Básica e da Estratégia Saúde da Família no Sistema Único de Saúde. Saude Debate 2014; 38(103):900-916.

44. Rosa RS. Desafios para o financiamento da saúde com a PEC55. Rev ADverso 2016; 223:33-36.

45. Freitas JH, Almeida PRB. A PEC 55 (241) e seus impactos sobre os direitos sociais. Rev Eletrônica Mestrado Direito UFAL 2017; 7(2):166-168.

46. Brasil. Emenda Constitucional no 95, de 15 de dezembro de 2016. Altera o Ato das Disposições Constitucionais Transitórias, para instituir o Novo Regime Fiscal, e dá outras providencias. Diário Oficial da União 2016; 15 dez.

47. Queiroz MDFM, Silva JLM, Figueiredo JS, Vale FFR. Eficiência no gasto público com saúde: uma análise nos municípios do Rio Grande do Norte. Rev Econômica Nordeste 2016; 44(3):761-776.

48. Franco TB. As Redes na Micropolítica do Processo de Trabalho em Saúde. In: Pinheiro R, Matos RA, organizadores. Gestão em Redes: práticas de avaliação, formação e participação na saúde. Rio de Janeiro: IMS, UERJ; 2006. p. 459-474.

49. Maissiat GS, Lautert L, Dal Pai D, Tavares JP. Contexto de trabalho, prazer e sofrimento na atenção básica em saúde. Rev Gaúcha Enferm 2015; 36(2):42-49.

Artigo apresentado em 09/11/2017

Aprovado em 04/06/2018

Versão final apresentada em 06/06/2018 